\title{
IMPLEMENTASI QUICK RESPONSE (QR) CODE PADA APLIKASI VALIDASI DOKUMEN MENGGUNAKAN PERANCANGAN UNIFIED MODELLING LANGUAGE (UML)
}

\author{
${ }^{[1]}$ Novan Adi Musthofa, ${ }^{[2]}$ Siti Mutrofin, ${ }^{[3]}$ Mohamad Ali Murtadho \\ ${ }^{[1],[2],[3]}$ Universitas Pesantren Tinggi Darul 'Ulum Jombang
}

\begin{abstract}
Abstrak: Dengan berkembangnya teknologi informasi, sering sekali terjadi penyelewengan dokumen terutama pada dokumen-dokumen cetak. Dokumen merupakan salah satu data yang sangat penting, karena dokumen merupakan sumber informasi yang diperlukan oleh suatu instansi, organisasi, negara, maupun individu. Tanpa dokumen, maka seseorang akan kehilangan data-data yang diperlukan untuk kegiatan di masa yang akan datang. Pemalsuan dokumen sangat mudah dilakukan dengan cara meniru bentuk serta isi dari suatu dokumen. Penelitian sebelumnya pernah dilakukan, namun dalam objek yang berbeda. Pemalsuan dokumen dapat diatasi dengan menggunakan Quick Response $(Q R)$ Code. QR Code mampu menyimpan semua jenis data, seperti data angka/numerik, alphanumeric, biner, kanji/kana. Selain itu QR Code memiliki tampilan yang lebih kecil daripada barcode. Untuk dapat membuat QR Code suatu dokumen maka dibuatlah sebuah aplikasi yaitu aplikasi Validasi Dokumen. Aplikasi Validasi Dokumen dirancang dengan menggunakan metode waterfall serta menggunakan perancangan Unified Modelling Language (UML). Bahasa pemrograman yang digunakan yaitu bahasa pemrograman PHP: Hypertext Preprocessor (PHP) dengan database MySQL. Sebelum QR Code dibuat, terlebih dahulu data dokumen dienkripsi dan kemudian dijadikan QR Code. Hasil pemindaian QR Code berupa Uniform Resource Locator (URL) yang mengarah pada data dokumen. Ketika URL dijalankan pada web browser, sistem melakukan deskripsi pada URL, kemudian dicocokkan dengan database, dan selanjutnya ditampilkan ke web browser. Hasil akhir aplikasi Validasi Dokumen berupa QR Code yang digunakan untuk menyimpan URL yang menunjukkan bahwa dokumen memang benar-banar dokumen yang resmi (bukan ilegal) dari suatu instansi. Pada uji coba penelitian ini juga dilakukan perbandingan kinerja dengan 3 aplikasi yang sejenis, 3 aplikasi pembanding tersebut dipilih karena memiliki hasil visual QR Code yang hampir mirip, namun jika dilakukan scanning memiliki hasil yang berbeda, karena fiturnya juga berbeda. Berdasarkan hasil pengujian dengan 3 pembanding aplikasi yang sejenis, dengan menggunakan aplikasi yang diusulkan dalam penelitian ini, pemalsuan dokumen dapat dihindari dengan menggunakan aplikasi Validasi Dokumen selama tidak ada ikut campur orang dalam (superadmin/admin) dalam melakukan praktik pemalsuan dokumen. Pada penelitian selanjutnya dapat dilakukan perbaikan kelemahan aplikasi ini, yaitu agar tidak menampilkan URL, namun hasil pemindai QR Code, langsung dapat menampilkan detail isi dokumen.
\end{abstract}

Kata Kunci: Dokumen, pemalsuan, pemalsuan dokumen, QR Code, Unified Modelling Language

\section{PENDAHULUAN}

\section{A. Latar Belang Masalah}

Seiring perkembangan teknologi dan informasi, pemalsuan dokumen sangat mudah dilakukan. Sehingga dapat memberikan celah untuk melakukan praktik pemalsuan dokumen. Pemalsuan dokumen umumnya dilakukan dengan memanipulasi isi dari dokumen, yaitu membuat dokumen baru dengan desain dan tampilan yang serupa dengan aslinya. Dokumen merupakan salah satu data yang sangat penting, karena merupakan sumber informasi yang diperlukan oleh suatu instansi, organisasi, negara, maupun individu. Tanpa dokumen, akan kehilangan data-data yang diperlukan untuk kegiatan di masa yang akan datang.

Quick Response (QR) Code dapat dibuat suatu aplikasi validasi dokumen yang dapat mengetahui apakah dokumen tersebut asli atau palsu. QR Code reader dan generator merupakan perangkat lunak 
yang beredar bebas, sehingga semua orang dapat membuat dan memindai sebuah QR Code, sehingga praktik pemalsuan masih dapat dilakukan terhadap konten QR Code. Untuk itu perlu dilakukan proses enkripsi konten sebelum diubah menjadi QR Code. Tujuan enkripsi adalah agar konten yang diubah ke dalam QR Code tidak dapat diidentifikasi secara langsung format dan isinya oleh orang lain.

QR Code mampu menyimpan semua jenis data, seperti data angka/numerik, alpanumerik, biner, kanji/kana. Selain itu QR Code memiliki tampilan yang lebih kecil daripada barcode. Hal ini dikarenakan QR Code mampu menampung data secara horizontal dan vertikal, jadi secara otomatis ukuran dari tampilannya gambar QR Code bisa hanya sepersepuluh dari ukuran sebuah barcode. Tidak hanya itu, QR Code juga tahan terhadap kerusakan, sebab QR Code mampu memperbaiki kesalahan sampai dengan 30\% tergantung dengan ukuran atau versinya. Oleh karena itu, walaupun sebagian simbol QR Code kotor ataupun rusak, data tetap dapat disimpan dan dibaca. Tiga tanda berbentuk persegi di tiga sudut memiliki fungsi agar simbol dapat dibaca dengan hasil yang sama dari sudut manapun.

Untuk mengantisipasi terjadinya praktik pemalsuan dokumen, maka dilakukan pengamanan dengan cara menyisipsikan suatu objek pengenal seperti nama pemilik, ID, atau tanda tangan yang digunakan untuk mencocokkan konten yang tertulis pada dokumen, yang kemudian akan disisipkan dan diproses sedemikian rupa menjadi sebuah kode yang akan diidentifikasi dan dicocokkan. QR Code merupakan teknik yang mengubah data tertulis menjadi kode-kode 2 dimensi yang tercetak kedalam suatu media yang lebih ringkas (Rahmawati dan Rahman, 2011). Dengan QR Code, informasi keaslian dokumen tersebut dibuat menjadi lebih sederhana atau simpel tanpa mengetikkan informasi kode validasi pada dokumen tersebut.

\section{B. Validasi}

Istilah Validasi pertama kali dicetuskan oleh Dr. Bernard T. Loftus, Direktur Food and Drug Administration (FDA) Amerika Serikat pada akhir tahun 1970-an, sebagai bagian penting dari upaya untuk meningkatkan mutu produk industri farmasi. Hal ini dilatar belakangi adanya berbagai masalah mutu yang timbul pada saat itu yang mana masalah-masalah tersebut tidak terdeteksi dari pengujian rutin yang dilaksanakan oleh industri farmasi yang bersangkutan. Selanjutnya, Validasi juga diadopsi oleh negara-negara yang tergabung dalam the Pharmaceutical Inspection Co-operation/Scheme (PIC/S), Uni Eropa (EU) dan World Health Organization (WHO). Bahkan, Validasi merupakan aspek kritis (substantial aspect) dalam penilaian kualitas industri farmasi yang bersangkutan.

Terdapat banyak definisi dan pengertian tentang validasi. US FDA (Badan pengawasan Obat dan Makanan, Amerika Serikat) dalam The FDA's 1987 Guideline mendefinisikan validasi sebagai: "Establishing documented evidence, which provides a high degree of assurance that a spesific process will consistently produce a product meeting its pre-determined spesifications and quality characteristics."

Sedangkan WHO mendefinisikan sebagai: "A documented act of providing that any procedure, process, equipment, material, activity or system, actually leads to the expected result." (Samuel, 2011).

Badan POM RI (Anonim, 2006) memberikan definisi validasi sebagai: "Tindakan pembuktian dengan cara yang sesuai bahwa tiap bahan, proses, prosedur, kegiatan, sistem, perlengkapan atau mekanisme yang digunakan dalam produksi maupun pengawasan mutu akan senantiasa mencapai hasil yang diinginkan." (CPOB: 2006).

Dari beberapa pengertian diatas dapat diambil kesimpulan Validasi adalah tindakan pembuktian yang dilakukan sesuai dengan prosedur bahwa suatu data/dokumen benar-benar sesuai dengan data/dokumen asli yang sah. 


\section{Dokumen}

Menurut Louis Gottschalk (Nofentri, 2013) pengertian dari kata dokumen seringkali digunakan para ahli dalam dua pengertian, yaitu:

1) Sumber tertulis bagi informasi sejarah sebagai kebalikan dari pada kesaksian lisan, artefak, peninggalan-peninggalan terlukis, dan petilasan-petilasan arkeologis.

2) Diperuntukan bagi surat-surat resmi dan surat-surat negara seperti surat perjanjian, undang-undang, hibah, konsesi, dan lainnya.

Lebih lanjut, Gottschalk menyatakan bahwa dokumen (dokumentasi) dalam pengertiannya yang lebih luas berupa setiap proses pembuktian yang didasarkan atas jenis sumber apapun, baik itu yang bersifat tulisan, lisan, gambaran, atau arkeologis.

Dari pengertian yang telah dijabarkan oleh Louis Gottschalkk dapat disimpulkan bahwa pengertian dari dokumen adalah segala jenis catatan tertulis, gambar atau rekaman yang berkaitan dengan keperluan pengelolaan baik bersifat hardcopy ataupun softcopy.

\section{Quick Response (QR) Code}

QR Code merupakan teknik yang mengubah data tertulis menjadi kode-kode 2-dimensi yang tercetak kedalam suatu media yang lebih ringkas. QR Code adalah barcode 2-dimensi yang diperkenalkan pertama kali oleh perusahan Jepang Denso-Wave pada tahun 1994. Barcode ini pertama kali digunakan untuk pendataan invertaris produksi suku cadang kendaraan dan sekarang sudah digunakan dalam berbagai bidang. QR adalah singkatan dari Quick Response karena ditujukan untuk diterjemahkan isinya dengan cepat. QR Code merupakan pengembangan dari barcode satu dimensi, QR Code salah satu tipe dari barcode yang dapat dibaca menggunakan kamera handphone. (Rouillard,2008).

QR Code mampu menyimpan semua jenis data, seperti data angka/numerik, alphanumeric, biner, kanji/kana. Selain itu QR Code memiliki tampilan yang lebih kecil daripada barcode. Hal ini dikarenakan QR Code mampu menampung data secara horizontal dan vertikal, jadi secara otomatis ukuran dari tampilannya gambar QR Code bisa hanya seperspuluh dari ukuran sebuah barcode. Tidak hanya itu QR Code juga tahan terhadap kerusakan, sebab QR Code mampu memperbaiki kesalahan sampai dengan 30\% tergantung dengan ukuran atau versinya. Oleh karena itu, walaupun sebagian simbol QR Code kotor ataupun rusak, data tetap dapat disimpan dan dibaca. Tiga tanda berbentuk persegi di tiga sudut memiliki fungsi agar simbol dapat dibaca dengan hasil yang sama dari sudut manapun. (Rahmawati \& Rahman, 2011).

Versi simbol QR Code berkisar dari Versi 1 ke Versi 40. Setiap versi memiliki konfigurasi modul yang berbeda atau jumlah modul (Modul ini mengacu pada titik-titik hitam dan putih yang membentuk QR Code). "Konfigurasi Modul" mengacu pada jumlah modul yang terkandung dalam simbol, dimulai dengan Versi 1 ( 21 x 21 modul) sampai ke Versi 40 (177 x 177 modul). Setiap nomor versi lebih tinggi terdiri dari 4 modul tambahan per samping.

Setiap versi simbol QR Code memiliki kapasitas data yang sesuai dengan jumlah data, jenis karakter dan tingkat kesalahan koreksi. Untuk pemeriksaan data dengan kapasitas maksimum ditentukan pada setiap versinya. Untuk versi dan kapasitas data maksimum, maka jumlah data dan modul akan meningkat sehingga simbol QR Code semakin besar (Rahmawati \& Rahman, 2011).

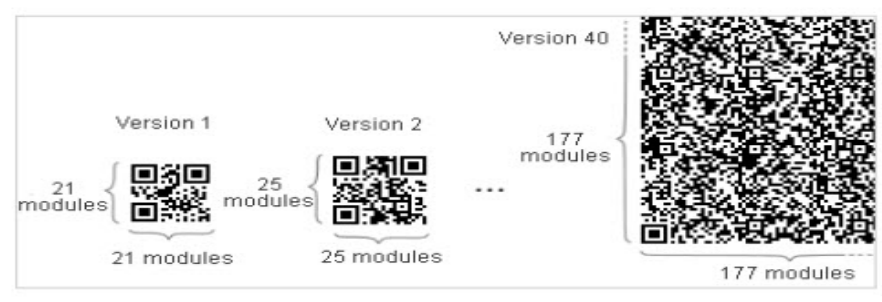

Gambar 1. Versi simbol QR Code 
QR Code memiliki kemampuan mengoreksi kesalahan untuk mengembalikan data jika kode kotor atau rusak. Empat tingkat kesalahan koreksi yang tersedia bagi pengguna, tingkatan ini mampu mengoreksi kesalahan pada QR Code. Faktor lingkungan dan ukuran QR Code perlu dipertimbangkan untuk mengetahui tingkat kesalahan. Tingkat $\mathrm{Q}$ atau $\mathrm{H}$ dapat dipilih jika kondisi lingkungan kotor yang akan menyebabkan QR Code mengalami kerusakan, sedangkan tingkat L dapat dipilih jika kondisi lingkungan bersih dengan jumlah data yang besar. Tingkat $\mathrm{M}$ adalah tingkat yang paling sering digunakan. Berikut tabel koreksi kesalahan QR Code (Rahmawati \& Rahman, 2011).

\begin{tabular}{|cc|}
\hline TABEL 1. KOREKSI KESALAHAN PADA QR CODE \\
\hline \multicolumn{2}{|c|}{ Kapasitas koreksi kesalahan QR Code } \\
\hline Level L & Dapat Mengoreksi Kesalahan Sampai 7\% \\
Level M & Dapat Mengoreksi Kesalahan Sampai 15\% \\
Level Q & Dapat Mengoreksi Kesalahan Sampai 25\% \\
Level H & Dapat Mengoreksi Kesalahan Sampai 30\% \\
\hline
\end{tabular}

\section{E. Use Case Diagram}

Use Case Diagram digunakan untuk menggambarkan siap saja yang dapat mengelola sistem dan apa saja yang dapat dilakukan. Use Case Diagram aplikasi validasi dokumen dapat dilihat pada Gambar 2. Pada gambar tersebut terdapat 3 aktor, yaitu: superadmin, admin, dan user.

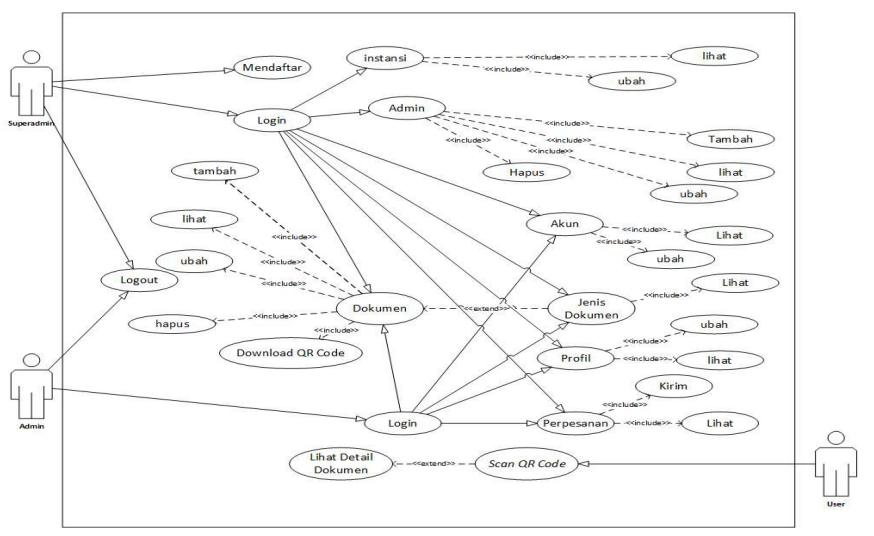

Gambar 2. Use case diagram aplikasi

\section{F. Activity Diagram}

Activity Diagram menggambarkan aktivitas yang terjadi ketika proses penambahan data dokumen serta pembuatan QR Code. Activity Diagram dapat dilihat pada Gambar 4.

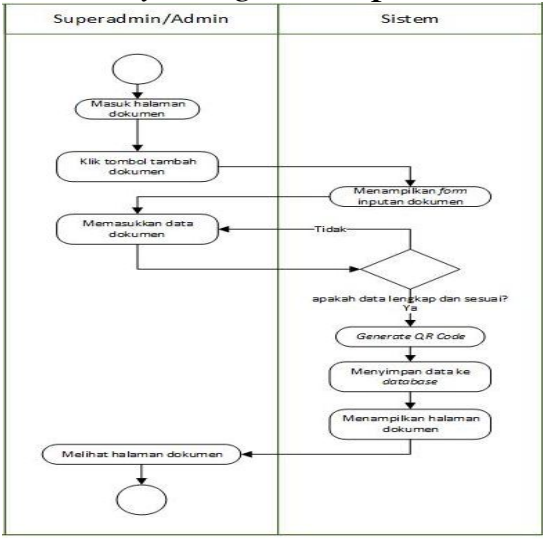

Gambar 3. Activity Diagram pembuatan QR Code 


\section{G. Flowchart}

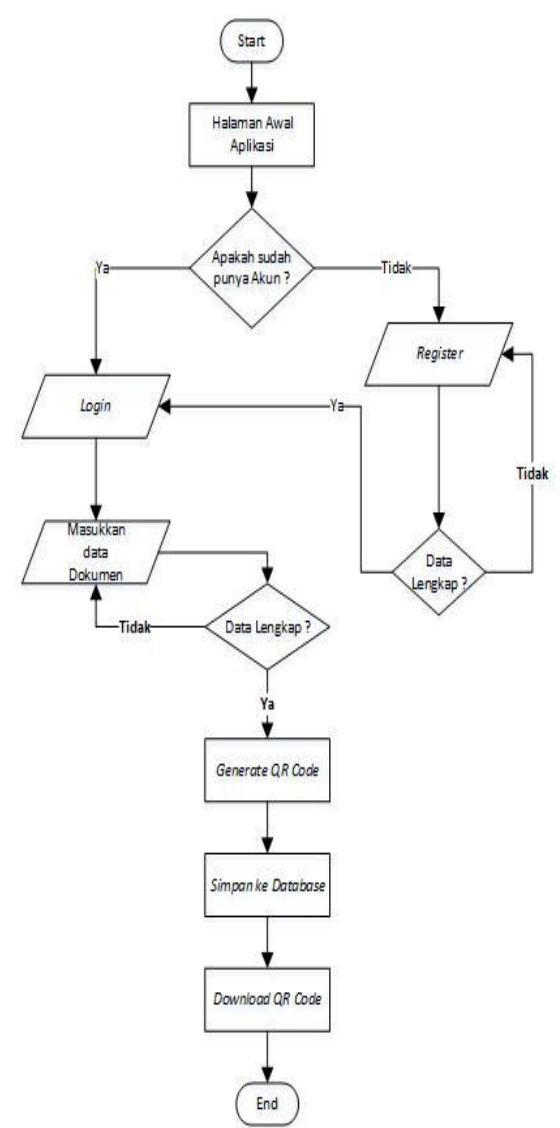

Gambar 4. Flowchart sistem diusulkan

Sistem yang diusulkan yaitu aplikasi berbasis web yang digunakan untuk membuat QR Code. Flowchart sistem yang diusulkan dapat dilihat pada Gambar 3. Ketika aplikasi pertama kali diakses, pengguna dihadapkan pada halaman awal aplikasi. Jika belum memiliki akun, maka pengguna diharuskan mendaftar terlebih dahulu pada sistem. Jika sudah memiliki akun, langsung saja memilih tombol login. Ketika telah berhasil login ke sistem kemudian memasukkan data dokumen yang akan dibuatkan QR Code.

\section{H. Sequence Diagram}

Sequence Diagram digunakan untuk menggambarkan langkah-langkah yang terjadi ketika QR Code dibuat. Sequence Diagram dapat dilihat pada Gambar 5.

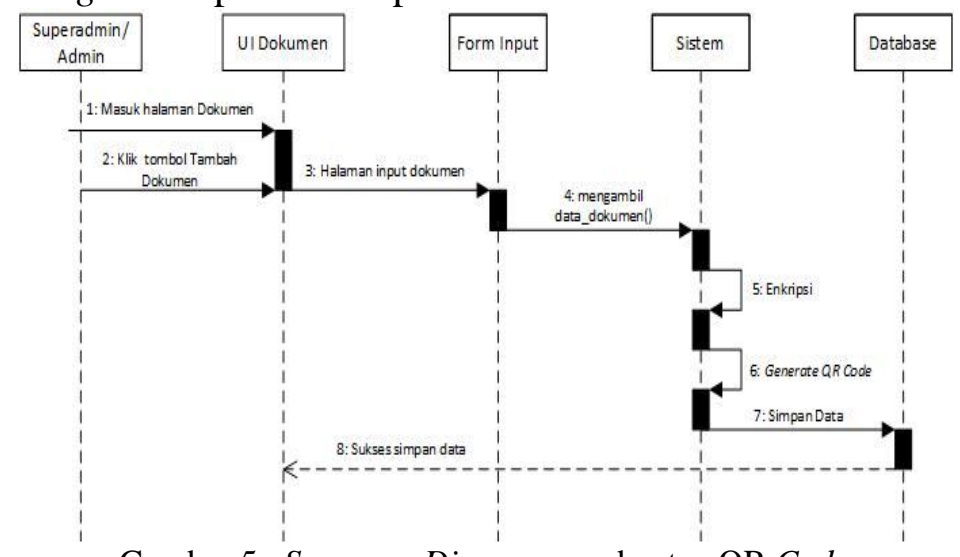

Gambar 5. Sequence Diagram pembuatan QR Code 


\section{Metode Pengumpulan Data}

Dalam hal ini metode penelitian yang digunakan adalah metode dengan cara mengumpulkan dan menggambarkan data mengenai keadaan secara langsung dari lapangan atau tepatnya yang menjadi objek penelitian untuk mendapatkan data secara relevan.

Teknik pengumpulan data yang dilakukan dalam mencari dan mengumpulkan data serta mengolah informasi yang diperlukan menggunakan beberapa metode sebagai berikut :

\section{J. Metode Pengamatan (Observasi Research)}

Merupakan cara pengumpulan data dimana peneliti tidak memiliki kendali sama sekali terhadap pemunculan respon objek yang diamati, kecuali dalam menentukan faktor yang diamati dan memeriksa ketelitian data. Penulis melakukan pengumpulan data dengan cara mengamati dokumendokumen yang digunakan untuk praktik pemalsuan serta apa saja hal-hal yang dapat dimanipulasi dalam praktik pemalsuan.

\section{K. Metode Wawancara (Interview)}

Wawancara adalah metode pengumpulan data dengan cara mencari informasi dengan mengajukan pertanyaan kepada pihak-pihak yang diminta untuk melakukan praktik pemalsuan (untuk keperluan sampelisasi pemalsuan).

\section{Metode Studi Pustaka (Library Research)}

Yaitu memperoleh data dengan cara membaca dan mempelajari buku-buku (perpustakaan) dan literature-literature (internet) yang berhubungan dengan teori dan laporan penelitian ini. Metode study pustaka dilakukan untuk menunjang metode wawancara dan observasi yang telah dilakukan. Pengumpulan informasi yang dibutuhkan dalam mencari referensi-referensi yang berhubungan dengan penelitian yang dilakukan.

\section{HASIL DAN PEMBAHASAN}

Setelah sistem dianalisa dan dirancang secara rinci, maka akan menuju tahap selanjutnya yaitu tahap implementasi. Implementasi merupakan tahap penerjemahan perancangan berdasarkan hasil analis kedalam suatu bahasa pemrograman tertentu serta penerapan perangkat lunak yang dibangun pada lingkungan yang sesungguhnya sehingga siap untuk dioperasikan. Implementasi bertujuan untuk mengkonfirmasi modul - modul perancangan, sehingga pengguna dapat memberikan masukan kepada pembangun sistem.

\section{A. Implementasi Antarmuka}

Implementasi antarmuka meliputi semua tampilan yang akan ditampilkan oleh aplikasi. Berikut adalah tampilan antarmuka tersebut:

1. Halaman Utama

Halaman Utama adalah halaman awal ketika membuka aplikasi ini, berisi pilihan yaitu register dan login. Tampilan halaman awal dapat dilihat pada Gambar 6.

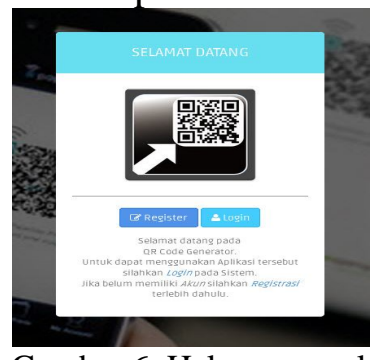

Gambar 6. Halaman awal 
Penjelasan: pada halaman awal ini pengguna dihadapkan pada 2 pilihan, yaitu register dan login. Register digunakan untuk melakukan proses pendaftaran pada aplikasi sedangkan login digunakan untuk masuk pada aplikasi.

\section{Halaman Register}

Halaman register digunakan untuk melakukan pendaftaran pengguna baru. Penguna yang belum memiliki akun maka diharuskan mendaftar terlebih dahulu. Halaman register dapat dilihat pada Gambar 4.2.

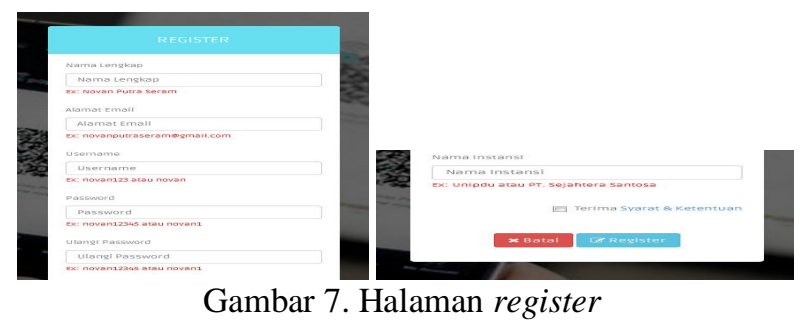

Keterangan: ketika pengguna melakukan pendaftaran system akan melakukan pengecekan pada form inputan pendaftaran. Jika data telah sesuai dengan permintaan kemudian sistem melanjutkan proses pendaftaran. Untuk verifikasi pendaftaran, sistem mengirimkan sebuah link aktivasi akun melalui email yang dimasukkan saat melakukan pendaftaran.

\section{Halaman Login}

Halaman login digunakan untuk masuk pada aplikasi. Ketika pengguna sudah memiliki akun, maka pengguna bisa login menggunakan akun yang didaftarkan pada sistem. Halaman login dapat dilihat pada Gambar 7.

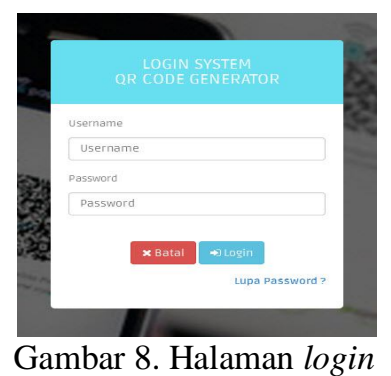

Keterangan: ketika hendak melakukan login pengguna diminta memasukkan username dan password sesuai dengan username dan password saat mendaftar pada sistem.

\section{Halaman Jenis Dokumen}

Halaman jenis dokumen digunakan untuk menampilkan jenis-jenis dokumen yang terdapat pada sistem. Jenis-jenis dokumen tersebut meliputi jenis-jenis dokumen yang sering digunakan oleh universitas. Halaman jenis dokumen dapat dilihat pada Gambar 4.4.

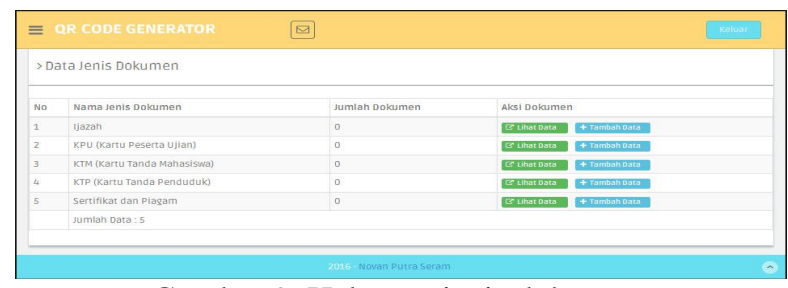

Gambar 9. Halaman jenis dokumen 
Keterangan: jenis-jenis dokumen yang terdaftar pada sistem memiliki tombol-tombol yang dapat digunakan untuk mengelola data dokumen. Tombol-tombol tersebut yaitu lihat data dan tambah data.

\section{B. Pengujian Sistem}

Pengujian terhadap implementasi sistem aplikasi validasi dokumen dilakukan menguji fungsionalitas sistem aplikasi pakah sudah sesuai dengan sekenario perancangan yang telah dilakukan sebelumnya.

Untuk dapat menguji fungsionalitas sistem aplikasi langkah pertama yang harus dilakukan adalah mendafar hosting untuk mendapat domain. Langkah kedua adalah meng-upload rancangan aplikasi, langkah ketiga adalah merubah koneksi disamakan dengan yang ada pada hosting selanjutnya langkang keempat masuk pada alamat yang sudah didapat dari hosting (http://qrcode-dokumen.com). Dalam pengujian fungsionalitas perangkat lunak ini menggunakan metode pengujian blackbox.

Pengujian Blackbox adalah pengujian yang sistemnya tanpa memperhatikan struktur logika internal perangkat lunak. Metode ini digunakan untuk mengetahui apakah perangkat lunak berfungsi dengan benar. Pada metode ini data uji dibangkitkan, dieksekusi pada perangkat lunak dan kemudian keluaran dari perangkat lunak dicek apakah telah sesuai dengan yang diharapkan atau tidak.

Pengujian login adalah pengujian yang diakukan pada halaman login. Pengujian yang dilakukan dapat dilihat pada Tabel 2 .

TABEL 2. PENGUJIAN LOGIN

\begin{tabular}{|c|c|c|c|c|c|}
\hline No & Inputan & Test Case & Hasil yang diharapkan & Hasil pengujian & Kesimpulan \\
\hline \multirow[t]{5}{*}{1} & Username & Dikosongkan & $\begin{array}{l}\text { Tampil peringatan harus } \\
\text { diisi }\end{array}$ & Sesuai harapan & Diterima \\
\hline & & $\begin{array}{l}\text { Diisi menggunakan } \\
\text { karakter selain } \\
\text { huruf dan angka }\end{array}$ & Menerima inputan & Sesuai harapan & Diterima \\
\hline & & $\begin{array}{l}\text { Diisi menggunakan } \\
\text { email }\end{array}$ & Menerima inputan & Sesuai harapan & Diterima \\
\hline & & $\begin{array}{l}\text { Diisi menggunakan } \\
\text { selain huruf, angka } \\
\text { dan email karakter }\end{array}$ & $\begin{array}{l}\text { Tampil peringatan karakter } \\
\text { diperbolehkan berupa } \\
\text { huruf, angka dan atau } \\
\text { email }\end{array}$ & Sesuai harapan & Diterima \\
\hline & & $\begin{array}{l}\text { Diisi sesuai dengan } \\
\text { username yang asli }\end{array}$ & Sistem menerima inputan & Sesuai harapan & Diterima \\
\hline \multirow[t]{4}{*}{2} & Password & Dikosongkan & $\begin{array}{l}\text { Tampil peringatan harus } \\
\text { diisi }\end{array}$ & Sesuai harapan & Diterima \\
\hline & & $\begin{array}{l}\text { Diisi menggunakan } \\
\text { karakter selain } \\
\text { huruf dan agka }\end{array}$ & $\begin{array}{l}\text { Tampil peringatan karakter } \\
\text { diperbolehkan berupa } \\
\text { huruf dan atau angka }\end{array}$ & Sesuai harapan & Diterima \\
\hline & & $\begin{array}{l}\text { Diisi sama persis } \\
\text { dengan username }\end{array}$ & $\begin{array}{l}\text { Tampil peringatan } \\
\text { username dan password } \\
\text { salah }\end{array}$ & Sesuai harapan & Diterima \\
\hline & & $\begin{array}{l}\text { Diisi dengan } \\
\text { password yang asli }\end{array}$ & Sistem menerima inputan & Sesuai harapan & Diterima \\
\hline
\end{tabular}




\section{KESIMPULAN}

Berdasarkan pembahasan yang telah di jabarkan sebelumnya, maka dapat di ambil kesimpulan sebagai berikut:

1. Aplikasi validasi dokumen dibuat menggunakan bahasa pemrograman PHP dengan database MySQL.

2. Aplikasi validasi dokumen mampu melakukan enkripsi dan dekripsi data dalam bentuk URL (Uniform Resource Locator) untuk kemudian di ubah menjadi sebuah QR Code.

3. Aplikasi validasi dokumen telah berhasil membatasi masukan sebagaimana mestinya. Baik panjang pendeknya karakter maupun bentuk-bentuk karakter yang diperbolehkan.

4. Aplikasi-aplikasi pembuat QR Code yang pernah ada tidak bisa menyimpan data dokumen seperti aplikasi validasi dokumen. Aplikasi-aplikasi tersebut hanya membuat beberapa teks dan URL yang dijadikan QR Code.

5. Pembuatan URL menjadi QR Code dapat dilakukan oleh aplikasi-aplikasi sebelumnya, namun URL tidak sama seperti URL yang dihasilkan oleh aplikasi Validasi Dokumen.

Aplikasi validasi dokumen hanya mampu menangani 5 (lima) jenis dokumen baik dokumen untuk keperluan pendidikan maupun untuk keperluan swasta. Untuk pengembangan selanjutnya diharapkan bisa memperbaiki kekurangan dan kelemahan yang ada pada aplikasi validasi dokumen. Kekurangan yang terletak pada penambahan jenis dokumen baik dalam bentuk statis maupun dinamis serta tampilan (template) untuk masing-masing jenis dokumen. Kemudian bisa menambahkan dalam bentuk aplikasi Android (apk) sehingga pengguna (client) tidak bisa melihat URL yang dikirimkan untuk mengambil data dokumen.

\section{DAFTAR PUSTAKA}

Rahmawati, Anita., Rahman, Arif. 2011. Sietem Pengamanan Keaslian Ijasah Menggunakan QR-Code dan Algoritma Base64. Program Studi Sistem Informasi, Universitas Ahmad Dahlan.

Rouillard, J., 2008, Contextual QR Codes, Proceedings of the Third International Multi - Conference on Computing in the Global Information Technology, ICCGI, Athens, Greece.

Samuel. (22 Maret 2011). Apa Itu Validasi? Diperoleh dari http://samuel.blog.undip.ac.id/2011/03/22/apa-itu-validasi/.

Utami Nofentri Sulistia. 2013. Rancang Bangun Aplikasi Manajemen Dokumen Berbasis Web pada PT. Boma Bisma Indra. Sekolah Tinggi Manajemen Informatika \& Teknik Komputer. Surabaya. 